\title{
O PROCESSO DE LEITURA COMPARTILHADA EM AMBIENTE DIGITAL
}

\author{
Eunice Polonia - PPG Letras/UFRGS - euniceamazonas@gmail.com \\ Patrícia da Silva Campelo Costa - PPGIE/ UFRGS - patricia.campelo@yahoo.com
}

Resumo: Este trabalho tem como propósito investigar como ocorre a leitura em ambiente digital, quando textos em língua estrangeira são produzidos a fim de serem compartilhados entre alunos que utilizam um editor eletrônico de texto coletivo. Partindo da noção de comunidades de prática, observa-se que a presença do leitor/colega, atuando como o interlocutor para o qual um texto é escrito, pode ter influência sobre o processo de escrita de aprendizes em ambiente digital, visto que a leitura passa a ser parte vital do processo de compartilhamento de produções textuais. Desse modo, são apresentados dados que refletem as interações, em meio eletrônico, entre alunos de língua estrangeira, que atuam como leitores e autores de textos produzidos no editor de texto coletivo. A partir do exame dessas interações, podemos observar que houve um feedback mútuo por parte dos alunos, que atuaram como revisores, leitores e apreciadores dos textos de seus colegas, construindo uma aprendizagem significativa em meio digital.

Palavras-chave: leitura, ambiente digital, editor de texto coletivo.

\section{THE PROCESS OF SHARED READING ON DIGITAL ENVIRONMENT}

\begin{abstract}
This research has the aim of investigating how reading occurs on digital environment when texts in a foreign language are written and shared among students who use a collaborative text editor. Focusing on the notion of community of practice, we can observe that the presence of a reader/colleague acting as interlocutor can have an influence on the process of writing by learners on digital environment, since reading is a vital step through the process of sharing textual productions. This way, we present data which reflects interactions among foreign language students, in electronic means, who act as readers and authors of texts produced in the collaborative text editor. Through the exam of these interactions, we can perceive there was a mutual feedback among students, who had the roles of reviewers and readers, building a meaningful learning on digital environment.
\end{abstract}

Keywords: reading, digital environment, collaborative text editor

\section{Introdução}

Para que tarefas em colaboração configurem momentos de prática relevante ao aprendizado do aluno, é essencial a formação de comunidades de prática de 
aprendizado. $\mathrm{Na}$ aprendizagem em ambiente digital, a constituição de comunidades virtuais de aprendizagem guia a realização e, por vezes, o envolvimento dos alunos com a tarefa. Segundo Norton e Toohey (2001), a noção advinda de Lave e Wenger (1991) acerca das comunidades de prática mudou o foco das questões relativas ao aprendizado, que tinham anteriormente como intenção estudar as características de personalidade e os estilos de aprendizagem de cada aluno. A atenção, então, voltou-se para a investigação de como a organização de comunidades fornece posições para o engajamento de indivíduos nas comunidades de prática. Assim, a partir da formação e engajamento dos alunos em suas comunidades de aprendizagem, o processo interlocutório de leitura pode se tornar significativo de modo a promover feedback que possa auxiliar na produção de textos.

Nos dados aqui analisados, foram observadas as etapas de reformulação colaborativa em ambiente digital de textos escritos individualmente pelos alunos. A ferramenta de editor de texto coletivo utilizada, ETC ${ }^{1}$, concebida inicialmente para a produção de textos coletivos, foi aplicada, nesta pesquisa, em uma etapa posterior ao processo de composição, constituindo um momento no qual os leitores de um texto tinham oportunidade de prover feedback de forma colaborativa, editando esse texto original e fornecendo comentários. Após essa etapa, um dos estágios analisados foi a discussão síncrona em um programa de mensagens instantâneas $\left(\mathrm{MSN}^{2}\right)$, na qual pares de alunos, após lerem o mesmo texto de um colega, discutiram a produção a fim de negociarem as escolhas feitas pelo autor do texto, de modo a ratificá-las e/ou sugerir mudanças.

Conforme Braine (1997), produções escritas manipuladas em meio digital podem aumentar a confiança dos alunos e, desse modo, instigar o provimento de feedback por parte dos leitores. Assim, nesta pesquisa a leitura é vista como um processo de interlocução, no qual há participação e interação ativa entre autores e leitores, visto que os textos são escritos em ambiente digital de modo a serem compartilhados entre colegas interlocutores que podem discutir essa produção. Desse modo, o processo de criação textual não se limita a ser um produto corrigido por um professor, mas adquire o papel de trabalho processual, passível de ser influenciado pela leitura de outros sujeitos. Dessa maneira, a partir dos dados aqui analisados, observamos o dispositivo digital como um meio facilitador para a construção de novas relações de sentido.

\section{Complexidade e Leitura}

Conforme Vetromille-Castro e Axt (2007, p. 96), “a constituição e a manutenção das comunidades virtuais de aprendizagem estão ligadas não somente a elementos e ferramentas que constituem a prática pedagógica, mas sobretudo à proposta que permeia ações e usos dos recursos." Portanto, apesar de o contexto digital de aprendizagem ser composto de características complexas, que dificultam o caráter de previsibilidade em relação a quais reações possam ter os alunos frente a determinadas tarefas, atividades que possuam teor interativo parecem mais propensas a facilitar ocasiões de aprendizagem.

Podemos aproximar a noção de leitura à teoria da complexidade, iniciada nos estudos da física e posteriormente discutida também no campo das ciências humanas. Segundo Larsen-Freeman (1997), a aleatoriedade gerada por sistemas complexos veio a ser chamada caos, conceito que viria como uma alternativa para um pensamento linear e 
reducionista que dominava a ciência. Nesse sentido, para a teoria da complexidade, o comportamento de seus sistemas complexos surge da interação entre seus componentes (ou agentes).

De acordo com Polonia (2003, p. 42),

o caos como aleatoriedade gerada pelos sistemas complexos relaciona-se não a um grau de desorganização máxima, mas sim ao funcionamento de uma delicadíssima rede de equilíbrio mantida a partir da dinamicidade de elementos intercomunicantes.

O processo de leitura de um texto escrito pode ser analisado a partir da teoria dos sistemas complexos como a movimentação através de possíveis interpretações de um trecho textual sendo processado. $\mathrm{O}$ ato de ler muda à medida que o processo de leitura coadapta-se às compreensões atuais do texto integral, pois o sentido do todo vai sendo construído a partir do processamento de suas partes (Larsen-Freeman e Cameron, 2008). Segundo essas autoras, o texto pode conter partes extremamente abertas a múltiplas interpretações, enquanto outras levam a interpretações estáveis.

A atividade de leitura aqui é entendida como um processo de interlocução ou de confronto de interlocutores em uma interação não só do leitor com o texto, mas com outros sujeitos (Orlandi, 1996, p.9). Portanto, não se busca o sentido ou a compreensão do texto nele mesmo, mas na rede entre o leitor, o texto e o autor nos contextos histórico-sociais da leitura. Segundo Bakhtin (1997), pelas condições que envolvem esses elementos, cada nova leitura do mesmo texto proporciona diferentes interpretações, de forma que não há uma leitura única e passiva. A interação ocorre a partir do conhecimento do gênero discursivo utilizado, ou seja, do tipo estável de enunciado construído historicamente nas interações sociais.

O processo de leitura compartilhada entre colegas pode ser considerado um sistema complexo e instável, sujeito às características desse sistema tais como dinamicidade, não-linearidade, imprevisibilidade, sensibilidade a fatores externos e auto-organização (Larsen-Freeman, 1997). O caráter de não-linearidade, segundo Larsen-Freeman, refere-se ao fato de o efeito não ser sempre proporcional à causa. Por sua vez, a imprevisibilidade se relaciona à noção de condições iniciais de um processo, visto que os sistemas são sensíveis a essas condições e qualquer mudança, por mais mínima que seja, pode influenciar uma modificação no que poderia ser previsível inicialmente. Justamente à questão de ser condicionado a qualquer alteração, relacionase a característica de ser sensível a fatores externos. Vetromille-Castro e Axt (2007, p. 100), ao comparar as comunidades virtuais de aprendizagem com os sistemas complexos, afirmam que essas comunidades podem ter "perturbações que levam à sua própria reestruturação [...] que leva a outro traço complexo - a auto-organização."

A auto-organização é caracterizada como um processo de mudança de fase, conduzido pelas propriedades dinâmicas de um sistema, sem haver influência de forças externas organizadoras (Larsen-Freeman e Cameron, 2008). Assim, a auto-organização pode levar a um novo fenômeno chamado emergência, durante o qual o que emerge como resultado de uma mudança de fase é diferente do que havia anteriormente. Destarte, todas essas características dos sistemas complexos se entrelaçam de modo a configurar também peculiaridades do processo de compartilhar textos e leitura no ambiente digital, assim como são características da formação de comunidades de aprendizagem online. 
É interessante observar que durante a realização de tarefas, em plataformas ou ferramentas digitais de aprendizagem, o aluno tem a oportunidade de contribuir, ler e reler o que foi postado, visto que o meio eletrônico oferece a permanência do registro. Esse aspecto oferece um ir e vir do aprendiz, que pode praticar a leitura, a releitura e assim reconstruir seus conceitos devido à permanência das contribuições de todos. $\mathrm{O}$ aluno pode, então, intensificar seu processo de reflexão durante a leitura de outros textos, a fim de que o próprio processo de aprendizagem seja repleto de construções e desconstruções dialógicas de conceitos (Bakhtin, 1997). Esse processo de releitura e consequente análise fomenta os processos de construção e desconstrução de conceitos sobre leitura e escrita, que são avaliados pelo aluno também de acordo com as opiniões e participações do outro.

\section{Feedback e Compartilhamento}

Para o presente trabalho, a noção de feedback se alia à proposta de Paiva (2003, p. 221), a qual considera esse evento no contexto online como uma:

reação à presença ou ausência de alguma ação com o objetivo de avaliar ou pedir avaliação sobre o desempenho no processo de ensino aprendizagem e de refletir sobre a interação de forma a estimulá-la, controlá-la ou avaliá-la.

Assim, conforme proposto pela autora, o feedback não deve se basear somente em um processo de correção, mas deve incorporar também mensagens que motivem e contribuam para a aprendizagem do aluno. Desse modo, a leitura do outro tem influência direta sobre a escrita de um texto, visto que o processo de autoria também passa a ser compartilhado a partir da interferência do interlocutor/leitor. Ramal (2002) salienta a noção de autoria em rede baseando-se na teoria bakhtiniana de polifonia e, desse modo, afirma que "o texto eletrônico subverte a tradição escrita e propõe um novo conceito ainda não definido de originalidade, de autoria e mesmo de anterioridade". Assim, a idéia de autoria perpassa o fundamento de que a linguagem influencia e é influenciada pelo social, fazendo com que autores também sejam vistos como sujeitos influenciados por outras vozes, os quais atuam em um mundo em rede de escrita colaborativa. Para Behar e Siluk (2005), a noção de rede, quando sob o ponto de vista da informática na educação, supera a idéia de interconexão entre computadores, visto que abarca a visão de interação entre usuários que se transformam em agentes. No entanto, ainda é difícil incorporar a idéia de coletividade na escrita em contextos tradicionais nos quais os alunos estão acostumados a trabalhar individualmente com textos lidos (ou corrigidos) apenas pelo professor.

Incluir no contexto escolar discussões sobre autoria coletiva, leitura compartilhada e cooperação na produção textual parece ser o primeiro passo a ser dado pelo professor que pretende implantar tarefas focalizadas na discussão e análise de textos em ambientes digitais. Conforme Demo (2008, p. 1), apesar de querermos que todo o aluno se torne autor, "a autoria precisa ser relativizada, porque, mais que ser modo de se apropriar de idéias exclusivas, é, natural e tipicamente fenômeno participativo", visto que nossas idéias e declarações são essencialmente revestidas por um caráter culturalmente coletivo.

Waquil e Behar (2009) inclusive caracterizam o ambiente virtual de aprendizagem como uma mola propulsora de um "processo de virtualização" no qual "são exercidas diferentes formas de relação de tempo e de espaço que implicam 
profundas mudanças no processo de aprendizagem" (p. 147). Justamente essas alterações se refletem na contraposição com muitas práticas tradicionais de ensino que tendem a valorizar o produto elaborado pelos alunos, sem levar em conta o processo de criação e reelaboração dos textos. Nesse sentido, enquanto observamos que em certas situações no contexto escolar o feedback ainda é apenas corretivo, podemos observar que, muitas vezes, o feedback em ambiente digital tende a ser mais colaborativo, de modo crítico ou incentivador. Tal atitude pode ocorrer justamente pelo fato de o texto ter uma função interlocutória muito evidenciada na web, visto que a leitura é compartilhada por muitos leitores.

\section{Metodologia e Análise}

O estudo aqui apresentado ocorreu em uma disciplina semi-presencial (Estudos Complementares de Inglês II) da Graduação em Letras na UFRGS, com a utilização da plataforma digital Rooda, da ferramenta online ETC e do software MSN, restringindo nossa investigação aos dois últimos recursos digitais mencionados. No processo de análise com sete alunos que compunham a turma, foram investigadas discussões síncronas em pares (provenientes de interações através do MSN), assim como opiniões sobre os textos escritos pelos colegas (através de postagens na seção Comentários do ETC). A partir de tais dados foi feita uma análise descritiva e interpretativista do processo, com observação de como ocorreu a leitura a partir das sugestões e debates apresentados pelos alunos/leitores.

No decorrer desta pesquisa foi utilizada uma versão do editor de texto coletivo ETC que continha as seguintes funcionalidades relacionadas à produção de texto: a) Editar (a partir da qual múltiplos autores podiam interferir em um texto; b) Inserir seção; c) Histórico (na qual todas as edições ficavam armazenadas, contendo a data, hora e o autor de cada modificação); d) Lixeira; e) Restaurar Lixeira e f) Participação (na qual havia uma avaliação quantitativa da participação dos usuários). Nessa ferramenta, então, os alunos tiveram oportunidade de compartilhar suas produções com os colegas, assim como lerem os textos escritos pelos outros a fim de sugerir modificações e receber sugestões.

Cada aula focalizada na análise e discussão de características de cada gênero textual estudado na disciplina (resenha crítica de seriado/cinema e fanfiction $^{3}$ ) foi seguida da composição dos textos por parte dos alunos. Em um segundo momento, o qual é o foco desta pesquisa, os informantes realizaram a tarefa de leitura compartilhada e participação ativa nos textos dos colegas, em ambiente digital. Para tanto, além da utilização do ETC, a proposta era que os alunos utilizassem também uma ferramenta de interação síncrona, para discutir os textos de seus colegas e propor possíveis sugestões e/ou reformulações através de um software de comunicação instantânea (MSN).

A seguir, são apresentadas, respectivamente, as observações postadas na seção Comentários do ETC sobre duas produções: a) uma das resenhas escritas por uma aluna ${ }^{4}$ sobre o filme chamado Enchanted; b) uma fanfiction criada por outra estudante sobre Harry Potter.

\section{a)}

I liked this review, but I thought it got a little superficial after the first paragraph... not in a bad way, but you could have explored it a little more. For me it was like reading the back cover of a DVD, you know? 
Inserido por LAÍS em 01-04-2009.

I understand what you mean.It happened because I was afraid to give spoilers.

Inserido por BRUNA em 01-04-2009.

Well B!, I agree with LAÍS. You could talk a little more about everything, about the production, etc. But I love the thing about NY as a place with no happy end. And of course, the beginnig "once upon a time" was brilliant.

Inserido por GISELE em 02-04-2009.

b)

Awwww. Very nice! So cute

Inserido por LAÍS em 11-06-2009.

Wow, Gi! That's a really cute fic of one of my favorites Harry Potter's shippers! I love the dancing part! You are right: Lily and James are forever! They were happy while they lived. =) And that's make me remember that are dead. $=\mid$ Anyway... I just love the redhead and her's prongs. $M$

Inserido por GISELE em 12-06-2009.

hmmm...i would say that this story sounds very very romantic. I have some problems with a romantic plot, i mean, i almost hate them...it seams that they are fake, not real. But $i$ admire who is a bright-side person, that can see beyond real life and its miserable side. Well, thats a cute story, indeed and u did a good job, in my opinion. Congrats!

Inserido por POLIANA em 13-06-2009.

Observamos que tais comentários, a partir de uma leitura inicial, tiveram influência na produção dos alunos, visto que a maioria deles fez novas versões de seus textos a partir das opiniões emitidas pelos colegas. Além disso, em relação à leitura das fanfictions, percebemos que os comentários transparecem o conhecimento compartilhado por parte dos aprendizes, em relação às temáticas produzidas nas narrativas. Nesse caso, eles realmente se transformaram em leitores que estavam ali com o propósito de indicar melhoras, dar apoio ao autor (um dos pré-requisitos para a continuação de fanfictions) e destacar as qualidades da história, sem para isso conduzir uma carga avaliativa de alguém que corrige. Além disso, é interessante observar que na maioria dos comentários há um grande envolvimento dos leitores com a mídia original na qual a história é embasada. Assim, elas revelam ter conhecimento das tramas originais e dos personagens que formam tais enredos. Na realização dessa tarefa, os alunos/leitores demonstraram um alto grau de comprometimento na leitura, visto que submergiram nas histórias a ponto de não se preocuparem com algumas formas lingüísticas desviantes empregadas pelos autores dos textos.

Em relação às interações estabelecidas pelos aprendizes através do MSN, os alunos discutiram, em duplas, os textos dos colegas. Para exemplificação de alguns momentos, incluímos em seguida trechos de conversas síncronas entre os alunos da turma, que discutiam o processo de reformulação das fanfictions escritas por seus colegas. Conforme o trecho a seguir, observamos que durante o processo de discussão do texto, as alunas dão auxílio à atuação da outra ao propor edições, conferirem a concordância com a colega e discutir de modo colaborativo. Ambas interagentes discutem a estrutura textual, Bruna aponta para uma questão gramatical relativa ao uso 
do pronome e pede a certificação de sua interlocutora a fim de promover uma reformulação baseada em escolhas cooperativas. Nesse momento, o discurso sobre a negociação da aprendizagem vem à tona, pois a presença do outro se faz relevante no processo de reflexão e re-elaboração de conceitos.

\section{Bruna says:}

Max knew all of this. He knew his wife was sick and could not control his alters, but he was tired of living like this.

this part made me confused

Gisele says:

why?

Bruna says:

is not HER alters?

Gisele says:

yes it is

$\mathrm{Na}$ interação a seguir, as alunas mantêm um processo de consultar uma a outra quanto às estruturas lingüísticas que pensam ser desviantes. Elas se auto-corrigem, pedem a opinião uma da outra e confirmam suas hipóteses.

Laís says (21:29):

You are almost blinded for this look-like-a-rainbow-just-like-Amelie-Poulain-movie series

Laís says (21:29):

can $u$ say blinded for?

Poliana says (21:30):

vo checar

Laís says (21:30):

i think it's by

Poliana says (21:30):

it exists

Laís says (21:30):

like, $u$ can say you're blinded for life, but by the lights

Laís says (21:30):

but i dont think it means the same thing

Poliana says (21:30):

hmm

No excerto seguinte, uma das alunas inclusive menciona o mecanismo de noticing (Swain, 2001), segundo o qual o aprendiz percebe lacunas na sua produção. Nesse caso, baseado na análise da produção alheia, a aluna tem oportunidade de observar seus próprios erros ao entrar em contato com um processo de leitura, exame e reformulação. Há uma tomada de consciência em relação às lacunas na produção do próprio aprendiz a partir da leitura de outro texto.

\section{Gisele says:}

I couldn' see nothing wrong

Let's talk serious

I saw some mistakes that I do when I wrote. Some lack of attention

Desse modo, as interações entre os alunos podem indicar reflexão sobre suas próprias produções, ao mesmo tempo em que eles discutem as composições dos colegas. Segundo Larsen-Freeman e Cameron (2008), a emergência ocorre no aprendizado justamente quando novas questões fazem sentido, ocasião que os autores 
chamam de a-ha moment, na qual os aprendizes percebem pontos até então desconhecidos. Assim, o novo conhecimento pode influenciar a formação de novas conexões entre o saber construído e suas experiências prévias de aprendizado.

Além disso, os alunos, em certos momentos da leitura, também quiseram fazer edições no corpo do texto dos colegas, na ferramenta ETC. Mesmo com a edição, eles pareciam querer colaborar para a produção dando sua opinião, sem serem enfáticos ou impositivos. Em alguns momentos, eram visto comentários como o seguinte, indicando que a tarefa era participativa, sem ser avaliativa:

[EDIT laís: $i$ have some comments regarding grammar that $i$ put like this. $i$ don't if i'm right in all of them, though]

Tal enunciado foi incluído antes da edição no corpo de um texto (resenha) sobre o seriado House. A aluna diz ter comentários (não correções) a fazer em relação à gramática e completa dizendo que não está completamente certa sobre a correção. Nesse momento, observamos uma intenção de ser solidária com o autor daquele texto. Mesmo que a aluna/leitora esteja certa de suas modificações, o objetivo é não ser taxativo e avaliativo em relação ao texto do colega.

Para confirmar a evolução dos textos através do processo aqui apresentado, foram examinadas algumas das versões iniciais e finais das produções elaboradas pelos alunos do grupo. Gisele, por exemplo, utilizando todos os comentários dos colegas, reformulou sua resenha crítica sobre o seriado Pushing Daisies, eliminando todos os erros locais - palavras geradoras de inadequação semântica, frases confusas, etc - e incluindo frases explicativas, conforme sugestão dos colegas leitores. Outras modificações que atenderam à revisão dos colegas na formatação final foram a remoção de frases do texto, definidas como confusas por eles, e a melhora da estrutura elíptica. A aluna Bruna, autora da resenha de Enchanted, também reelaborou seu texto incluindo as sugestões da turma, tais como: colocação de informações mais técnicas sobre o filme, inclusão de curiosidades relativas ao elenco e inserção de características da obra que a aproximavam do gênero Disney. Ademais, Bruna retirou frases com informações dispensáveis e modificou o desenvolvimento do texto. Por sua vez, a aluna Lúcia reformulou os trechos que continham erros locais, seguindo indicações dos colegas.

Após a realização da tarefa, foram entregues questionários aos participantes da pesquisa, a fim de que suas impressões sobre o experimento fossem relatadas. Nos questionários protocolares, pode-se verificar, conforme o depoimento oferecido pelos alunos, suas opiniões sobre determinados aspectos referentes à utilização da ferramenta e à tarefa proposta. Para exemplificar uma das perguntas direcionadas aos alunos, ao final do experimento, tínhamos o seguinte questionamento: Você participou das interações com seus colegas, nas quais você deveria discutir os textos a serem reformulados. Qual sua opinião sobre essa experiência? Por sua vez, uma das alunas emitiu sua opinião: Achei interessante a experiência porque tivemos a oportunidade de defender e criticar as mudanças que estavam sendo discutidas e, depois da discussão, chegar em consenso com o grupo. Assim, o fator colaborativo da tarefa foi destacado pelos próprios participantes da disciplina, visto que o aspecto cooperativo da atividade proposta permeou todo o processo de produção e leitura dos textos. 


\section{Considerações Finais}

O trabalho aqui proposto tinha o objetivo de apresentar alguns dados e reflexões provenientes de uma tarefa focalizada no caráter interlocutório da leitura, que justamente pode ter influência sobre os processos de escrita na web. Durante o decorrer da pesquisa, a interação se deu de formas síncrona e assíncrona, e a tarefa, apoiada nas ferramentas digitais utilizadas, tinha como propósito gerar discussão sobre os processos de leitura, compartilhamento e produção de textos em ambiente digital. Para os alunos da pesquisa, a reflexão poderia se dar através da análise do texto dos colegas, assim como a partir do exame de sua própria produção, após apreciação dos leitores. A ferramenta que embasou o trabalho, ETC, contou com um sofware de interação síncrona (MSN) no decorrer das aulas. Pela análise dos dados, podemos perceber que houve oportunidade de reflexão sobre a produção dos gêneros específicos, a partir de uma relação vinculada ao feedback do leitor. Visto que nem em todos os contextos é possível a escrita de textos em conjunto, de modo colaborativo, o propósito era refletir como a etapa posterior a uma escrita individual pode se tornar uma fase de apreciação ou de reformulação, na qual o papel do interlocutor tem fundamental importância na produção.

Com a finalização deste trabalho, observa-se que o processo de intervenção coletiva em textos, no ambiente digital, não precisa focalizar um caráter corretivo de avaliação, como muitas vezes ocorre na produção textual em contexto escolar. É possível que o fato de o aluno se envolver com o texto, tanto como autor quanto como leitor, possa auxiliar no seu desenvolvimento como produtor e interlocutor crítico. Assim, a oportunidade de ter recebido um feedback não avaliativo do colega, pode ter uma influência positiva na escrita do aluno, que vê o ato de produção textual não mais como uma etapa prévia a uma simples avaliação, mas sim como uma prática significativa de criação a ser compartilhada na rede com interlocutores. Ademais, o fato de as postagens no ETC sobre as fanfictions serem similares às resenhas publicadas em sites de fanfiction, comprova o quanto a tarefa foi real para os aprendizes, aproximandose do que seria uma apreciação genuína dessas narrativas na web. $\mathrm{Na}$ análise completa dos dados ${ }^{5}$, provenientes das interações síncronas e das postagens assíncronas, foram encontradas evidências de que uma proposta pedagógica em ambiente online de aprendizagem fomenta a participação do aluno de modo ativo e autônomo na leitura de textos dos seus colegas. Desse modo, podemos observar indícios de potencialização do papel participativo e autônomo do aluno a partir de uma tarefa que requeria colaboração entre os aprendizes, visto que esses estudantes atuaram como interlocutores reais dos textos dos colegas.

\footnotetext{
${ }^{1}$ Editor de texto coletivo desenvolvido pelo NUTED - Núcleo de Tecnologia Digital aplicada à Educação - da Universidade Federal do Rio Grande do Sul, coordenado pela Prof ${ }^{\mathrm{a}}$ Dr $^{\mathrm{a}}$ Patrícia Behar.

${ }^{2}$ MSN Messenger, atualmente nomeado Windows Live Messenger - http://www.msn.com/

${ }^{3}$ Gênero textual da internet baseado na escrita de narrativas por fãs de alguns dos ícones da cultura popular, como seriados, filmes e animes (animação japonesa). Na produção de fanfictions, os autores-fãs, tendo como ponto de partida a história original, podem aumentar ou modificar o roteiro das histórias, acrescentar novos personagens e modificar as relações entre os já existentes (Black, 2009).

${ }^{4}$ Por razões éticas de pesquisa, todos os nomes citados neste trabalho são fictícios.
} 
5 A análise completa dos dados desse estudo pode ser consultada em: COSTA, P. Feedback em ambiente digital: um processo interlocutório de leitura e produção escrita. Porto Alegre: UFRGS, 2010. Dissertação (Mestrado em Linguística Aplicada), Programa de Pós-Graduação em Letras, Universidade Federal do Rio Grande do Sul, 2010.

\section{Referências Bibliográficas}

BAKHTIN, M. Os gêneros do discurso. In: BAKHTIN, M. Estética da Criação Verbal. São Paulo: Martins Fontes, 1997.

BEHAR, P.; SILUK, A. Redes acadêmicas virtuais para a formação de professores. Revista Novas Tecnologias na Educação, Porto Alegre, v. 3, n. 1, 2005.

BLACK, R. Online fanfiction, global identities, and imagination. Research in the Teaching of English, v. 43, n. 4, p. 397-425, 2009.

BRAINE, G. Beyond word processing: networked computers in ESL writing classes. Computers and Composition, v. 14, n. 1, p. 45-58, 1997.

DEMO, P. Autoria. UNB, 2008. Disponível em: <http://www.eeducador.com/index.php/artigos-mainmenu-100/768-autoria-um-excelente-artigo-doprof-pedro-demo $>$. Acesso em: 2 set. 2009.

LARSEN-FREEMAN, D. Chaos/complexity science and second language acquisition. Applied Linguistics, v. 18, n. 2, p. 141-165, 1997.

LARSEN-FREEMAN, D.; CAMERON, L. Complex systems and applied linguistics. Oxford: Oxford University Press, 2008.

LAVE, J.; WENGER, E. Situated learning: legimate peripheral participation. Cambridge: Cambridge University Press, 1991.

NORTON, B; TOOHEY, K. Changing perspectives on good language learners. TESOL Quarterly, v. 35, n. 2, p. 307-322, 2001.

ORLANDI, E. P. Discurso \& leitura. São Paulo: Cortez, 1996.

PAIVA, V. Feedback em ambiente virtual. In: LEFFA, V. (Org.) Interação na aprendizagem das línguas. Pelotas: EDUCAT, 2003. p. 219-254.

POLONIA, E. Parâmetros para procedimentos pedagógicos na aprendizagem de inglês como língua estrangeira em uma rede telemática. Porto Alegre: UFRGS, 2003. Tese (Doutorado em Informática na Educação), Programa de Pós-Graduação em Informática na Educação, Universidade Federal do Rio Grande do Sul, 2003.

RAMAL, A. Educação na cibercultura: hipertextualidade, leitura, escrita e aprendizagem. Porto Alegre: Artmed, 2002.

SWAIN, M. Integrating language and content teaching through collaborative tasks. The Canadian Modern Language Review, v.58. n. 1, p. 44-63, 2001.

VETROMILLE-CASTRO, R.; AXT, M. 'Emergência' e a aprendizagem de (professores de) línguas em ambientes virtuais de aprendizagem. Informática na Educação: Teoria e Prática, Porto Alegre, v. 10, n. 2, p. 95- 106, jul./dez., 2007.

WAQUIL, M.; BEHAR, P. Princípios da pesquisa científica para investigar ambientes virtuais de aprendizagem sob o ponto de vista do pensamento complexo. In: BEHAR, P.(Org.). Modelos pedagógicos em educação a distância. Porto Alegre: Artmed, 2008. 